\title{
Mixed Assessment Method for Distant Learning: Challenges and Future Works
}

\author{
Rima Novirianthy ${ }^{1}$, Novi Maulina ${ }^{1 *}$, Marisa ${ }^{1}, Z^{2}$ ulfa Zahra $^{1}$, Ika Waraztuty ${ }^{1}$, Dedy \\ Syahrizal $^{1,}$ Maryatun $^{1}$ \\ ${ }^{1}$ Faculty of Medicine, Syiah Kuala University, Aceh \\ *Corresponding author.Email: novimaulina@unsyiah.ac.id
}

\begin{abstract}
Online teaching due to pandemic Covid-19 significantly impacted to medical education institution. In this study, we described our first experience of using mixed online student assessment methods in the setting of Covid-19 and evaluated student's perceptions about the examination, as challenges and future works. Our institution made an adjustment in student assessment format by randomizing 60-MCQ items performed by Google form, supervised simultaneously using Zoom application, and completing the assessment with an online oral examination where 2 lecturers gave 2 or 3 questions based on modules topic to each student. A limited number of MCQ items, network connectivity problems, and fraud risk were reported during the online MCQ examination. While scheduling oral examination earlier, difference perception in lecturer's scoring and bias risk due to items leakage were found as challenges in an online oral examination. These challenges will be considered to design a proper assessment method in near future works.
\end{abstract}

Keywords: Mixed assessment method, MCQ, oral examination, medical education, Covid-19 pandemic

\section{INTRODUCTION}

The corona virus SARS-CoV-2 pandemic has disrupted the social life, economy, and other governmental aspects. The enforcement of social distancing to slow the Covid-19 spreading to the most vulnerable populations and the manageable case load in a health center in a nation have led to an impact on the economy, healthcare, and in particular the education sector.[1]

Universities have halted non-essential services by restricting campus based teaching, and continuing courses through online resources. Online teaching platforms are beneficial due to their worldwide accessibility, ensuring that all medical students regardless of their current location are able to access webinars as they happen or can be recorded for later use. [1]-[5]

However, there was apprehension among medical students, and questions were raised regarding how examinations were taken place. [6] Additionally, there were worries of how their mental health would fare if given the online learning content, alongside concerns regarding their quality and preparedness for life as a qualified doctor.[7]

Assessment is an indispensable component of curriculum practice. In the education system, one of the prime considerations of teachers and medical students is the outcomes of learning, what ability students can demonstrate because of an increase in their knowledge and changes in understanding because of learning experiences. Concern for how learning takes place in higher education institutes and how instruction and assessment will affect the quality of learning, even in a pandemic era.[8], [9]

Due to the pandemic, many of the assessments and placements in the educational institutions have been affected with some being canceled, postponed, or adjusted in format. [10] Some institutions in the UK made a remote online assessment for 280 sixth-year medicine undergraduates through two online exams. [10], [11], [12] Our educational institution has been closed during mid of March, which was the seventh week 
of even semester. This has adversely affected the educational process in the mid and the third blocks of the semester on first, second, and third-year students. They were neuro-musculoskeletal and basic sense system (fifth block); digestive, endocrine, and clinical metabolism (eleventh block) and healthcare management, family medicine, biostatistics, and research methodology (seventeenth block).

While assessments of clinical, communication skills, and professionalism/ethics by objective structured clinical examinations (OSCEs) were canceled, summative assessment was adjusted to 60 online MCQs using google form with Zoom-supervised and online oral examination. In the pre-pandemic era, we prepared 100 multiple-choice questions (MCQs) by Computer Based Test (CBT format) for each summative block examination.

In the present study, we aim to describe our first experience of mixed online student assessment method in the setting of Covid-19, and evaluate the student's perception about the examination, as challenges and future works.

\section{METHOD}

The first online assessment during the pandemic was held in May for the mid-block examination of the semester. Four hundred and forty-seven students of 3 batches participated in the exam. The first-year students participated in 5th block exam; the second year students got the 11th block exam and the third-year students took the 17th block exam.

\section{Online Multiple Choice Questions (MCQ) Assessment}

We arranged 2 hours timed online MCQ assessment for each batch with half an hour for preparation (tools and briefing), 1 hour for students answering randomized-60 MCQ items by google form, and last half an hour for gathering paper works regarding official reports and finalization. The students had the simulation 2 days before the exam to get used to the application since Zoom was used to supervise students and items in Google form to be responded by students in one device. Students were told to use their PC or laptop, not a phone. Every 15 students and 1 supervisor were grouped in 1 WhatsApp group to update problems during the examination and to collect each student's integrity pact, statement form, and the picture of the student's current desk and room before the exam. They were also connected simultaneously in the Zoom breakout room to be supervised during the exam.

\section{Online Oral Examination}

For the online oral examination, 15 students were arranged in one group to be interviewed by 2 lecturers in 3 sessions. Each block team prepared the rules of the exam. The students and 2 lectures were grouped in 1 WhatsApp group to update information and test time for students. Each student was asked 2 or 3 questions of different block topic by 2 lecturers in average 15-20 minutes of time by Zoom application.

A questionnaire about student preparedness, challenges, and perception during the examination was prepared and administered via google forms to the students at the end of both tests. Student's responses were compiled using spreadsheets. Participant's information related to gender and their current location was shown in graph 1 . The detailed responses are depicted in table 1 .

\section{RESULT AND DISCUSSION}

Across 3 batches of students from the second, fourth, and sixth semesters, 464 medical undergraduate students enrolled in the classes; 447 provided their responses to the online MCQ questionnaire and 279 students responded to the oral examination questionnaire. Seventy-two percent (72\%) of MCQ examination participants were female students and $30 \%$ of students who responded the MCQ questionnaire were from outside of Aceh province.

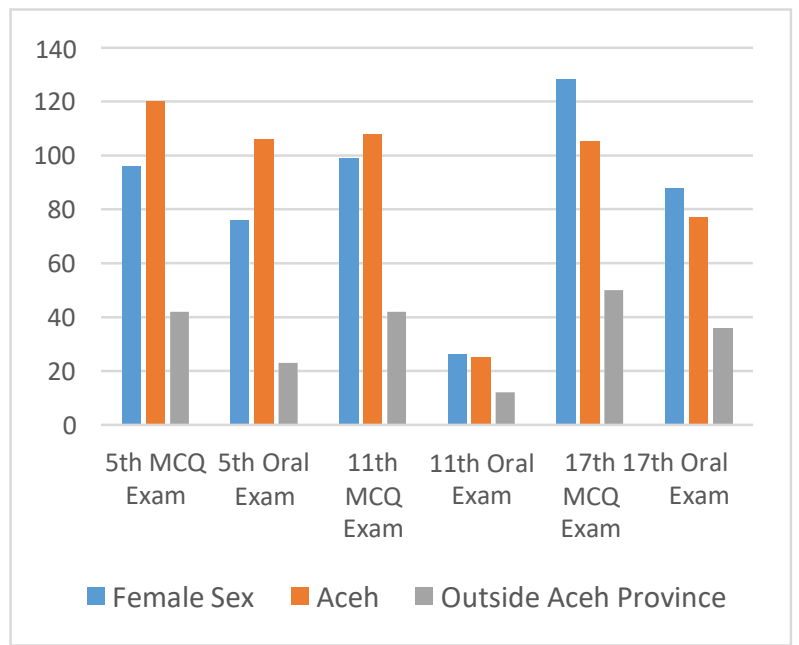

Graph 1. Student's gender and their location

According to student's responses in table 1, most of the students across batches were well prepared for studying learning materials and tools, and they understood the exam procedures. However, there were $25 \%$ of students in 11th batches did not really understand the oral examination procedures as it was the first experience using the online summative assessment method.

While many developed countries have wellestablished online and distant learning programs in place, it is not with most of the medical colleges in developing 
countries including Indonesia. Therefore, the challenges of sudden distant learning in developing countries are different from those developed. [13] Issues of internet connectivity and low bandwidth to get into $\mathrm{zoom}^{\mathrm{TM}}$ as supervised application during the online MCQ exam or during the oral exam were matters. Apart from anxiety feeling prior to the exam itself, most students especially for those students living in rural areas complained of this problem. [14] In fact, connection lost during the exam was reported by $43.3 \%$ and $39 \%$ of 11 th block students in the oral exam and online MCQ exam, respectively.

Table 1. Feedback on Online Examination by Medical Undergraduate

\begin{tabular}{|l|c|c|c|c|c|c|}
\hline & \multicolumn{5}{|c|}{ Agree (\%) } \\
\hline & \multicolumn{3}{|c|}{ Oral Exam (n=279) } & \multicolumn{2}{c|}{ MCQ Exam (n=464) } \\
\hline & $\begin{array}{c}5^{\text {th }} \\
\text { Block }\end{array}$ & $\begin{array}{c}\mathbf{1 1}^{\text {th }} \\
\text { Block }^{\text {th }}\end{array}$ & $\begin{array}{c}\mathbf{1 7}^{\text {th }} \\
\text { Block }\end{array}$ & $\begin{array}{c}\mathbf{5}^{\text {th }} \\
\text { Block }\end{array}$ & $\begin{array}{c}\mathbf{1 1}^{\text {th }} \\
\text { Block }\end{array}$ & $\begin{array}{c}\mathbf{1 7}^{\text {th }} \\
\text { Block }\end{array}$ \\
\hline Exam Preparation & & & & & & \\
\hline a)Learning Materials & 95 & 97.3 & 92 & 96.3 & 98 & 95.5 \\
\hline $\begin{array}{l}\text { b)Tools } \\
\text { Laptop/PC/Phone) }\end{array}$ & 95 & 97.3 & 94.6 & 96.9 & 97.3 & 93.5 \\
\hline $\begin{array}{l}\text { c)Understand Exam } \\
\text { procedures }\end{array}$ & 94.5 & 75.7 & 87.6 & 96.3 & 96.7 & 95.5 \\
\hline Anxiety feeling & 86.8 & 91.9 & 92.9 & 79 & 92.6 & 83.8 \\
\hline Connection lost & 16.3 & 43.3 & 29.2 & 24 & 39 & 37 \\
\hline The exam goes well & 93.8 & 89.2 & 80.5 & 90.7 & 84.7 & 83.2 \\
\hline
\end{tabular}

In spite of challenges found during the exam, more than $80 \%$ of each batch's students revealed that the examination goes well. As concerns the preferred mix of assessment formats, we found that the share of online MCQ and online oral examination format examinations meet student's expectations. This student's mix assessment format preference was also shown in the previous study. [15]

The corona virus pandemic has introduced novel methods of delivering education to medical students. Lectures have rapidly been developed to be delivered online as webinars using various platforms such as Zoom, with such technologically enhanced approaches already being proven to have high levels of engagement with medical students. [16]

Here also we listed some challenges we found and student's suggestion in the questionnaire:

\section{Online MCQ examination Challenges and Future Works}

\section{a) Limited number of MCQ items}

Students felt sixty-MCQ items do not represent the whole knowledge from the modules of the block. Since we adjusted the exam by choosing 60 of 100 items based on topics and oral exams as a completion, the students prefer to have more items to improve the possibility to have higher scores in the MCQ block examination. We will consider this in the next block examination because it will also make them connect to supervised application longer.

\section{b) Network connectivity}

Distant learning owes a lot in network availability. Issues of internet connectivity and low bandwidth to get into Zoom ${ }^{\mathrm{TM}}$ as a supervised application during the MCQ exam were matters. [13], [14] Students signed out of Zoom $^{\mathrm{TM}}$ unintendedly (and sometimes unawarely). Then they will report this to the supervisor by WhatsApp and try to reconnect. It frequently happened during the exam for the same student or different student. Bad weather also will affect the network. We often had heavy rain with strong winds in the exam period and it ended up with power outage leads to an internet connection problem. [14] In our experience, we should wait and re-supervise a student only by WhatsApp because she lost connection and has to restart answering the items, while all of her friends finished. For the next exam, we can't guarantee this problem would not occur, but we can prepare the tool properly by having PC/laptop or phone fully charged and preparing cellular data instead of Wi-Fi.

c) Fraud risk during online MCQ examination.

The reliability of online assessment systems also should be taken into account, as the students do exams remotely with the availability of network connection, learning materials, and the possibility of cheating. [17] We anticipated this by randomizing the items and made time limitations with table and room pictures were taken by each student before the exam, and asking the students to sign an integrity pact and statement form to be honest doing the exam.

Moving forward, we should ensure a robust system for student's remote examination setting and clear guidance on extenuating circumstances should be made. Although online assessments and teaching methods have become more prominent in the past decade, the COVID19 pandemic has enforced circumstances which may accelerate their widespread use in medical education.

\section{Online Oral examination challenges and Future Works}

\section{a) Scheduled Oral Examination}

As Computer-Based Examination in the prepandemic era, students hope online oral examination to be scheduled and announced earlier so that they can prepare themselves well. Once it was set as distant learning due to pandemic, the faculty stakeholder tried to find a feasible online assessment to be done and announced it to students right after the decision and preparation of method and IT. However, having an MCQ exam together with the first online oral exam of a broad block topic, students literally stay nervous to have lecturers asking them directly. Moving forward, we should be well prepared and include oral examination in 
a schedule. Since previous research findings showed that the assessment format will have a considerable influence on student's approaches to learning [15], we will consider announcing the schedule earlier at the beginning of the block.

b) Difference perception in lecturer's scoring and Fraud Risk due to Items Leakage

Cees van der Vleuten [18] stated that the utility of an assessment method depends on its reliability, validity, costs, educational impact, and its acceptability. As oral examinations could achieve long-term knowledge comparing to MCQ and SAQ (short answered questions), [15] it has been criticized due to low reliability, low validity, and examiners bias. [19], [20] Studies showed that most of the students prefer MCQ format to SAQs (Short answered questions) and oral examinations because MCQ seems easier to prepare for and easier to pass. [21], [22] However, as preferred mix assessment methods, most students choose MCQ as the main format assessment followed by an oral examination. Oral examinations itself believed could invoke long-term retention of medical knowledge more than MCQs and SAQs (Short answered questions) and they are more preferred than SAQ format. [15]

Moving forward, to minimize the lecturer's bias in the oral examination, each of the questions should be equipped with an assessment rubric or maximal score. More scenarios with items are implemented according to the schedule to reduce items leakage will be considered.

Assessment drives learning in all forms of education including medical education. [23] Optimization of assessment format is believed to enhance student's learning motivation during the pandemic era. In this study, we describe our institution's mixed assessment format during a pandemic by online MCQ and online oral examination. As we realized that online MCQ assessment alone had limitations, completion with the online oral examination which enables lecturers to evaluate students associative, strategic thinking and encourage them to pursue a deep level of understanding directly were acceptable.

\section{CONCLUSION}

This study described a mixed assessment method during the pandemic in our institution. We used online MCQs and oral examination to address learning goal and to enhance student's learning motivation despite limitations occurred during distant learning. Challenges were listed and as distant learning enforced longer, these will be a future opportunity to design proper assessment works.

\section{AUTHORS' CONTRIBUTION}

$\mathrm{RN}$ - contributed to the data collection, manuscript writing and concept

NM-contributed to the data analysis and manuscript writing

Ms-contributed to the questionnaire development and data collection

ZZ-contributed to manuscript writing and concept

IW-contributed to manuscript writing and concept

DS-contributed in data collection and concept

Mt-contributed in data collection and concept

\section{ACKNOWLEDGMENTS}

The authors thank the 447 medical students who responded to this survey, the assessment unit team, supervisors and lecturers who support our first online assessment format in covid-19 pandemic. The authors received no financial support for the research, authorship, and/or publication of this article.

\section{REFERENCES}

[1] Ahmed H, Allaf M, Elghazaly H. COVID-19 and Medical Education. The Lancet Infectious Disease. 2020 July; 20(7).

[2] Flaxman S, MIshra S, Gandy A, Juliette H, Unwin $\mathrm{T}$, Coupland $\mathrm{H}$, et al. Estimating the number of infections and the impact of non-pharmaceutical interventions on COVID-19 in European countries: technical description update. arXiv preprint arXiv:2004.11342. 2020 April.

[3] Singh K, Srivastav S, Bhardwaj A, dixit A, Misra S. Medical Education During Covid-19 Pandemic: a single institution experience. Indian Pediatric. 2020 July; 57(2).

[4] Ferrel MN, Ryan JJ. The Impact of COVID-19 on Medical Education. Cureu. 2020 March; 12(3).

[5] Rose S. Medical Student Education in the Time of COVID-19. JAMA. 2020 May; 323(21).

[6] Jamil Z, Fatima S, Saeed A. Preclinical Medical Student's Perspective on Technology Enhanced Assessment for learning. J Pak Med Ass. 2018 June; 68(6).

[7] Mahase E. Covid-19: Mental health consequences of pandemic need urgent research, paper advises. BMJ. 2020 April; 369(16).

[8] Mikre F. The roles of assessment in curriculum. Ethiop. J. Educ. \& Sc. 2010 March; 5(2).

[9] Maulina N, Novirianthy R. Item analysis and peerreview evaluation of specific health problems and 
applied research block examination. The Indonesian Hournal of Medical education. 2020 July; 9(2).

[10] Choi B, Choi B, Minocha A, Alhilani M, Nakhoul M, Mutengesa E. The impact of the COVID-19 pandemic on final year medical students in the United Kingdom: a national survey. BMC Medical Education. 2020 June; 20.

[11] Birch E, Wolf Md. A novel approach to medical school examinations during covid-19 pandemic. Medical Education Online. 2020 June; 25(3).

[12] Tapper J, Batty D, Savage. Medical students take final exams online for first time, despite student concern. The Guardian. 2020 April.

[13] Farooq F, Rathore FA, Mansoor SN. Challenges of Online Medical Education in Pakistan during Covid-19 Pandemic. Journal of the College of Physicians and Surgeons Pakistan. 2020 September; 30(1).

[14] Daroedono E, Siagian FE, Alfarabi M. The impact of COVID-19 on medical education: our student's perception. International Journal of Community Medicine and Public Health. 2020 July; 7(7).

[15] Holzinger A, Lettner S, Steiner-Hofbauer V, Melser MC. How to assess Perceptions and preferences of undergraduate medical students concerning traditional assessment. BMC Medical Education. 2020 September; 20.

[16] Poh-Sun G, John S. A vision of the use of technology in medical education after the covid-19 pandemic. MedEdPublish. 2020 March.

[17] Lee J, Kim RJ, Park SY, A.Henning M. Using technologies to prevent cheating in remote assessments during the COVID-19 pandemic. Journal of Dental Education. 2020 July.

[18] Van der Vleuten CP, Schuwirth LW. Assessing professional competence: from methods to programmes. Med Educ. 2005; 3.

[19] Colton T, Peterson OL. An assay of medical students' abilities by oral. J Med Educ. 1967; 11.

[20] Foster J T; Abrahamson, S; Lass, S; Girard, R; Gar ris, R. Analysis of an oral examination used in specialty board certification. J Med Educ. 1969; 10.

[21] Ibrahim NK, Al-Sharazi BM, Al-Asiri RA, Alotaibi NA, Al-Husaini WI, Al-Khajah HA. Perceptions of clinical years' medical students and interns towards assessment methods used in King Abdulaziz

University, Jeddah. Pak J Med. 2015 August.

[22] Amin TT, Kaliyadan F, Al-Muhaidib NS. Medical students' assessment preferences at King Faisal University, Saudi Arabia. Adv Med Educ Pract. 2011 March.

[23] Wormarld BW, Schoeman S, Somasunderam A, Penn M. Assessment drives learning: an unavoidable truth? Anat Sci Educ. 2009 October. 